\title{
Preparation, thermal insulation and flame retardance of cellulose nanocrystal aerogel modified by $\mathrm{TiO}_{2}$
}

\author{
Jing Luo ${ }^{1,2}$, Hua Wang ${ }^{1 *}$ \\ ${ }^{1}$ Metallurgical and Energy Engineering College, Kunming University of Science and Technology, Kunming 650093, China \\ ${ }^{2}$ Fire Protection Institute, Southwest Forestry University, Kunming 650024, China
}

Corresponding Author Email: lincoln558@163.com

https://doi.org/10.18280/ijht.360226

Received: 10 September 2017

Accepted: 25 February 2018

\author{
Keywords: \\ cellulose nanocrystal $(\mathrm{CNC}), \mathrm{TiO}_{2}$, \\ aerogel, flame retardance
}

\begin{abstract}
This paper successfully prepares $\mathrm{TiO}_{2}$-modified cellulose nanocrystal $(\mathrm{CNC})$ composite aerogel through in-situ synthesis of $\mathrm{TiO}_{2}$ in $\mathrm{CNC}$ solution and supercritical $\mathrm{CO}_{2}$ drying. Then, the structure, morphology, thermal insulation and flame retardance of $\mathrm{TiO}_{2} / \mathrm{CNC}$ composite were investigated through X-ray diffraction (XRD), scanning electron microscopy (SEM), thermogravimetry and differential thermal analysis (TG-DTA), and cone calorie measurement. The XRD and SEM spectra show that the $\mathrm{TiO}_{2}$-modified $\mathrm{CNC}$ aerogels exhibited a $3 \mathrm{D}$ network structure and underwent a decline in crystallinity through $\mathrm{TiO}_{2}$ doping and modification. The TG-DTG curves reveal that $\mathrm{TiO}_{2} / \mathrm{CNC}$ aerogels surpassed the $\mathrm{CNC}$ aerogel in thermal decomposition temperature. The cone calorie measurement indicates that $\mathrm{TiO}_{2} / \mathrm{CNC}$ aerogels lagged far behind the $\mathrm{CNC}$ aerogel in the PHRR. To sum up, the test results demonstrate that $\mathrm{TiO}_{2}$ doping and modification is an effective way to enhance the flame retardant and thermal insulation properties of cellulose aerogel. The research findings shed new light on the development of thermal insulation and fire-retardant clothing materials.
\end{abstract}

\section{INTRODUCTION}

Aerogel is a synthetic porous ultralight material derived from a gel, in which the liquid component for the gel has been replaced with a gas. With excellent thermal insulation and adsorption properties, this material enjoys broad application prospects in the fields of aerospace engineering, national defence, military industry, green building and environmental governance [1]. Aerogels mainly fall into four categories, namely, inorganic aerogel, organic aerogel, carbon aerogel and composite aerogel [2]. Among them, organic aerogel has attracted more and more attention thanks to its low dielectric constant, good mechanical properties, low thermal conductivity and flexible molecular designability [3].

One of the most popular organic aerogel is cellulose aerogel, which is highly biodegradable and biocompatible. Thus, cellulose aerogel has been widely used for environmental protection. Nevertheless, cellulose aerogel is a fire hazard, i.e. it is easy to combust and release lots of toxic fumes. To avoid the hazard, many scholars have tried to improve the thermal stability and flame retardance of cellulose aerogel [4]. For instance, Wu et al. [5] prepared $\mathrm{APP}-\mathrm{SiO}_{2}$ aerogel/poplar fireretardant composite by sol-gel method, and thus enhanced the thermal stability of the source material, as evidenced by the $28.1 \%$ reduction of weight loss rate at $700^{\circ} \mathrm{C}$ and the $5.4 \% \sim 31.9 \%$ increase of the residual carbon amount. Using sol-gel method, Hribernik et al. [6] developed a layer of $\mathrm{SiO}_{2}$ on the surface of regenerated cellulose fibres and found that the $\mathrm{SiO}_{2}$ coating elevated the initial decomposition temperature of fibres by $20^{\circ} \mathrm{C}$ and pushed up the ignition and radiance temperature of the residual coke (the corresponding exothermic peak increased by $20^{\circ} \mathrm{C} \sim 40^{\circ} \mathrm{C}$ ).
$\mathrm{TiO}_{2}$ is a green material with good human affinity, chemical stability, heat resistance and weather fastness [5]. The chemically-adsorbed water on the surface of $\mathrm{TiO}_{2}$ grains can interact with the hydroxyl groups in wood cellulose, allowing the grains to deposit on wood surface or enter cell cavities and even cell walls. These grains partially block the entry of water and oxygen into wood and increase the following parameters of the wood: swelling resistance, corrosion protection, thermal stability, limiting oxygen index and burning time [6].

Using the cellulose nanocrystal (CNC) solution, this paper carries out the in-situ synthesis of $\mathrm{TiO}_{2} / \mathrm{CNC}$ composite through the integration of aerogel preparation technique and the flame retardance principle of cellulose nanocrystal (CNC). On this basis, the $\mathrm{TiO}_{2} / \mathrm{CNC}$ composite cellulose aerogel was prepared by supercritical $\mathrm{CO}_{2}$ drying. Then, the author discussed the effects of $\mathrm{TiO}_{2}$ doping and modification on the structure, morphology, thermal stability and combustion performance of cellulose aerogel, aiming to enhance the flame retardance of cellulose aerogel through $\mathrm{TiO}_{2}$ modification. The research findings shed new light on the development of thermal insulation materials, high-temperature fire-resistant clothing materials, and high-temperature resistant equipment in China.

\section{EXPERIMENT}

\subsection{Methodology}

\subsubsection{Inorganic salt induced gelation}

The heavy presence of hydroxyl groups and the aggregation trend of cellulous molecules are the root causes of the conversion of cellulose solution into a gel. The gelation rate of 
cellulose solution hinges on the aggregation speed of cellulous molecules. According to the principle of colloidal stability, the electrolyte has an effect on the aggregation rate of colloidal particles. If the gelation takes place in an inorganic salt solution, the charge distribution of the original sol system will be changed by the electrolyte, pushing cellulose molecules closer to form a gel. The inorganic salt can induce and promote the gelation of cellulose solution, because it disrupts the charge distribution and destroys the stability of the original sol system.

\subsubsection{CNC preparation and hydrogel formation}

Mix $5 \mathrm{~g}$ poplar chips and $1.5 \mathrm{~mol} / \mathrm{L}_{8} \mathrm{~N}_{2} \mathrm{O}_{8} \mathrm{~S}_{2}$ solution in a $500 \mathrm{~mL}$ three-necked flask according to the solid-liquid ratio of 1:100 (g: $\mathrm{mL})$. Stir the mixture in a water batch at $70^{\circ} \mathrm{C}$ for 30min. Obtain CNC through centrifuge and drying. Prepare four CNC solutions, each of which contains $10 \mathrm{~g}$ CNC. Add $\mathrm{TiO}_{2}$ into three of these solutions by the proportions of $1 \mathrm{wt} \%$, $2 w t \%$ and $3 w t \%$, respectively. Perform ultrasonic treatment of the original $\mathrm{CNC}$ solution and each of the three $\mathrm{CNC} / \mathrm{TiO}_{2}$ solutions in an ice bath for $15 \mathrm{~min}$, followed by standing for 30min. Take the suspension of each solution and add it slowly into $0.25 \mathrm{~mol} / \mathrm{L} \mathrm{CaCl}_{2}$ solution. Allow the mixed solution stand for $48 \mathrm{~h}$ to ensure full gelation. In this way, spherical hydrogels were obtained by inorganic salt induced gelation.

\subsubsection{Gel displacement}

The gel displacement was conducted in multiple steps in tert-Butyl alcohol (TBA). Soak the prepared hydrogels in TBA solution (mass fraction: $25 \%$; temperature: $40^{\circ} \mathrm{C}$ ). Adjust the mass fraction of the TBA every $48 \mathrm{~h}(50 \%, 75 \%$, and $100 \%$, respectively). Without changing the other conditions, the above procedure eventually produces spherical CNC alcogels

\subsubsection{Supercritical $\mathrm{CO}_{2}$ drying}

Supercritical $\mathrm{CO}_{2}$ drying of the prepared $\mathrm{CNC}$ alcogels were performed using a supercritical fluid extractor (SFT-105, US). Heat the reactor to $40^{\circ} \mathrm{C}$. Add all $\mathrm{CNC}$ alcogels into the reactor (atmosphere: $\mathrm{CO}_{2}$; pressure: $12 \mathrm{MPa}$ ) and dry them for $3 \mathrm{~h}$ to obtain $\mathrm{CNC}$ aerogels. Denote the pure $\mathrm{CNC}$ aerogel, the $\mathrm{CNC}$ aerogel modified by $1 \mathrm{wt} \% \mathrm{TiO}_{2}$, the $\mathrm{CNC}$ aerogel modified by $2 \mathrm{wt} \% \mathrm{TiO}_{2}$, and the $\mathrm{CNC}$ aerogel modified by $3 \mathrm{wt} \% \mathrm{TiO}_{2}$, as $\mathrm{S}-0, \mathrm{~S}-1, \mathrm{~S}-2$ and $\mathrm{S}-3$, respectively.

\subsection{Performance testing and characterization}

Cut open the aerogel with a blade, fix it onto the sample holder with double-sided tape, and spray the sample with gold. Then, all samples were subjected to crystallinity tests using an Ultima IV X-ray diffractometer (XRD) under the following conditions: $\mathrm{Cu}-\mathrm{K} \alpha$ rays, filament current of $30 \mathrm{~mA}$, accelerating voltage of $40 \mathrm{kV}$, scanning step length of $0.02^{\circ}$, scanning range of $5 \sim 40^{\circ}$, and scanning speed of $5^{\circ} / \mathrm{min}$. The internal micro-morphology of the pure $\mathrm{CNC}$ aerogel and those modified with $\mathrm{TiO}_{2}$ were observed by field emission scanning electron microscope (LEO $1530 \mathrm{Vp}$, Germany).

The thermogravimetry and differential thermal analysis (TG-DTA) curve of each sample was measured by a thermogravimetric analyser (TG-209F3) in a nitrogen atmosphere at a flow rate of $30 \mathrm{~cm}^{3} / \mathrm{min}$. During the measurement, the temperature was increased from room temperature to $600^{\circ} \mathrm{C}$ at a heating rate of $15 \mathrm{~K} / \mathrm{min}$. The thermal conductivity coefficients of all samples were determined by QTM-500 rapid thermal conductivity meter
(Xufeng, China). The cone calorimeter test was conducted on a cone calorimeter according the ISO 5660-1 standard. The sample size was $100 \mathrm{~mm} \times 100 \mathrm{~mm} \times 10 \mathrm{~mm}$, and the radiant heat flux was $30 \mathrm{~kW} / \mathrm{m}^{2}$

\section{RESULTS AND ANALYSIS}

Figure 1 shows the SEM spectra of all four samples. As shown in Figure 1(a), the S- 0 sample had a 3D mesh structure inside and did not collapse. During the inorganic salt induced gelation, celluloses intertwined with each other via the hydrogen bonds of hydroxyl groups, forming a 3D network with cellulose as the skeleton. Meanwhile, gas-liquid interface and surface tension were eliminated by solvent displacement and supercritical $\mathrm{CO}_{2}$ drying, which prevents the internal structure destruction of alcogels during drying and protects the microstructure of $\mathrm{CNC}$ aerogel [7]. As shown in Figures 1 (b d), $\mathrm{TiO}_{2}$ grains were distributed inside $\mathrm{CNC}$ aerogel, and grew denser with the increase of the doping amount, indicating the successful doping of $\mathrm{TiO}_{2}$ in $\mathrm{CNC}$ aerogel. It can be noted that S-1 3 had a different 3D network structure from the S0. This agrees well with the reduced crystallinity of S-1 3 shown by the X-ray diffraction (XRD) test.
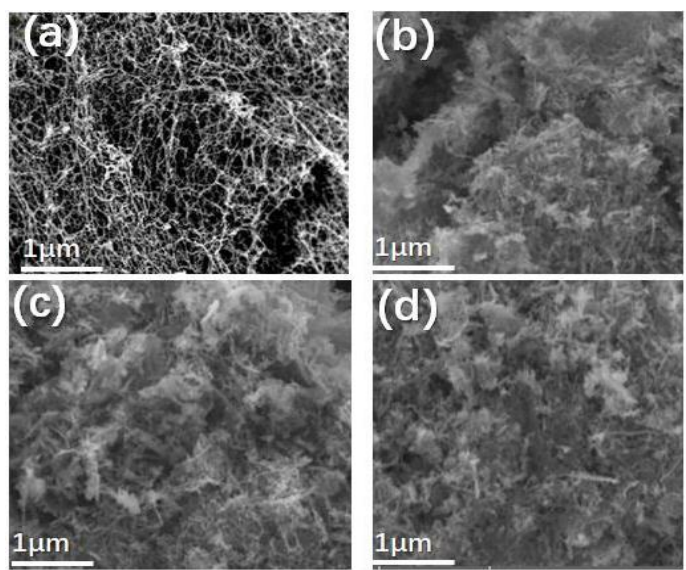

Figure 1. (a) Scanning electron microscopy (SEM) spectra of $\mathrm{S}-0$ and $(\mathrm{b} \sim \mathrm{d}) \mathrm{S} 1 \sim 3$

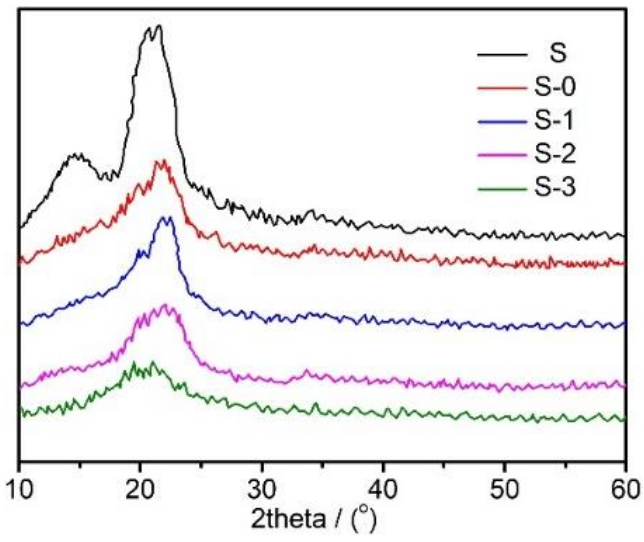

Figure 2. XRD spectra of cellulose (S) and all four samples

The XRD can characterize the crystal structure and form of CNC aerogel. The XRD spectra of cellulose (S) and all four samples (SO 4) are presented in Figure 2. It can be seen that $S$ had two distinct diffraction peaks $\left(15.17^{\circ}\right.$ and $\left.21.22^{\circ}\right)$, indicating that the crystal form of $\mathrm{S}$ is cellulose I crystal form. 
By contrast, the diffraction peaks of S- $0 \sim 4$ were respectively $21.31^{\circ}, 21.59^{\circ}, 21.58^{\circ}$, and $21.02^{\circ}$, revealing that the cellulose loses the cellulose I crystal form after the formation of aerogel. Meanwhile, the diffraction peaks of all samples were low in intensity and relatively wide. This means the cellulose is less crystallized after aerogel formation and the crystalline area of cellulose aerogel is destroyed. The destruction can be attributed to the cellulose dissolution process in the ionic liquid during aerogel formation [8]. In addition, no $\mathrm{TiO}_{2}$ diffraction peak was detected in the XRD test, owing to the small doping amount. Compared with the $\mathrm{S}-0$, the diffraction peaks of $S-1 \sim 3$ were of low intensity and gradually declining with the increase of the doping amount. Thus, $\mathrm{TiO}_{2} / \mathrm{CNC}$ aerogels are less crystallized than $\mathrm{CNC}$ aerogel, indicating that the crystalline area of cellulose aerogel is further destroyed after $\mathrm{TiO}_{2}$ modification. As a result, the aerogel burns more thoroughly after pyrolysis. This can be verified by the TG test.
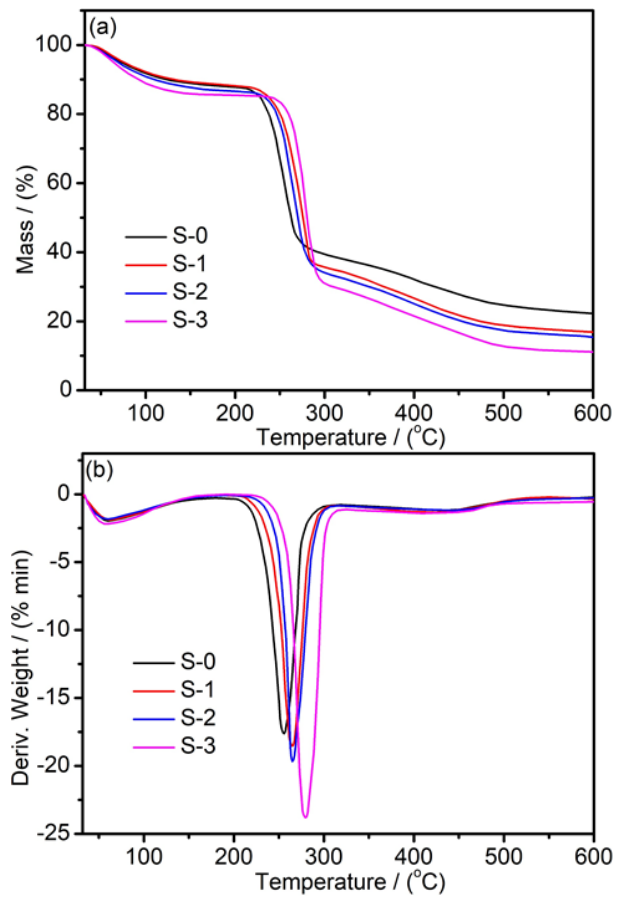

Figure 3. TG-DTG curves of all four samples

To disclose the impacts of $\mathrm{TiO}_{2}$ doping and modification on the thermal insulation of cellulose aerogel, all four samples were subjected to the TG analysis. The resulting TG-DTG curves are recorded in Figure 3. It can be seen from Figure 3(a) that the thermal-variation of weight can be divided into three phases for all samples. In the first phase $\left(<100^{\circ} \mathrm{C}\right)$ : the mass loss of the sample is resulted from the evaporation of adsorbed moisture; in the second phase $\left(200 \sim 350^{\circ} \mathrm{C}\right)$ : the mass loss of the sample is attributable to the pyrolysis of cellulose, including the depolymerization, dehydration, and decomposition of glucose molecular chains (the end product is carbonized residue); in the third phase $\left(>350^{\circ} \mathrm{C}\right)$ : the carbonized residue was mostly oxidized and decomposed into low molecular weight gas products, and the remaining part underwent aromatic cyclization, forming the graphite structure $[9,10]$. Note that the second phase can be further split into two sub-phases: in $200 \sim 270^{\circ} \mathrm{C}$, the alcoholic hydroxyl group was removed from the $\mathrm{C} 2$ position of some glucose units in the cellulose macromolecule; in $270 \sim 350{ }^{\circ} \mathrm{C}$, the alcoholic hydroxyl group was removed from the $\mathrm{C} 4$ position of some glucose units in the cellulose macromolecule, marking the fracturing of glyosidic bonds. The TG curves show that the thermal decomposition temperatures of S- 0, S-1, S-2, and S-3 were $213^{\circ} \mathrm{C}, 216^{\circ} \mathrm{C}, 223^{\circ} \mathrm{C}$, and $239^{\circ} \mathrm{C}$, respectively. Thus, $\mathrm{TiO}_{2}$ modification can increase the thermal decomposition temperature of cellulose, promote carbon formation in the matrix and enhance the thermal stability of the composite [11].

As shown in Figure 3(b), there was a peak in each DTG curve in $200 \sim 350^{\circ} \mathrm{C}$. The peak stands for the maximum weight loss rate, which corresponds to the maximum thermal decomposition rate (MTDR) temperature [12]. The MTDR temperatures of S-0, S-1, S-2 and S-3 were $255^{\circ} \mathrm{C}, 264^{\circ} \mathrm{C}$, $265^{\circ} \mathrm{C}$ and $280^{\circ} \mathrm{C}$, respectively. It can be seen that $\mathrm{TiO}_{2} / \mathrm{CNC}$ aerogels surpassed the CNC aerogel in the MTDR temperature. Meanwhile, the MTDR of cellulose aerogel increased with the doping amount of $\mathrm{TiO}_{2}$, revealing that the $\mathrm{TiO}_{2}$ doping and modification can effectively elevate the MTDR temperature and enhance the thermal insulation of cellulose aerogel.

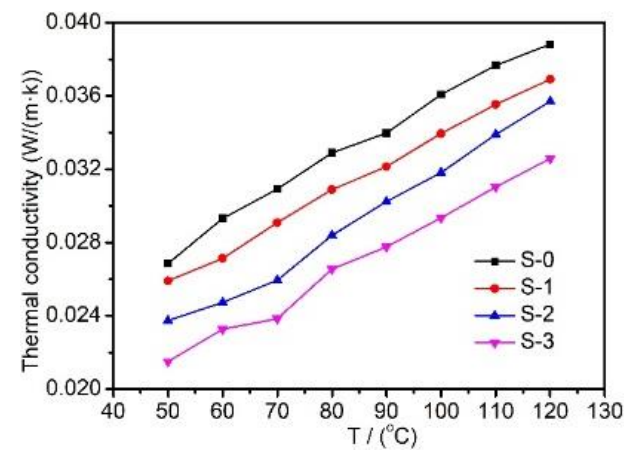

Figure 4. Thermal conductivity coefficient curves of all four samples

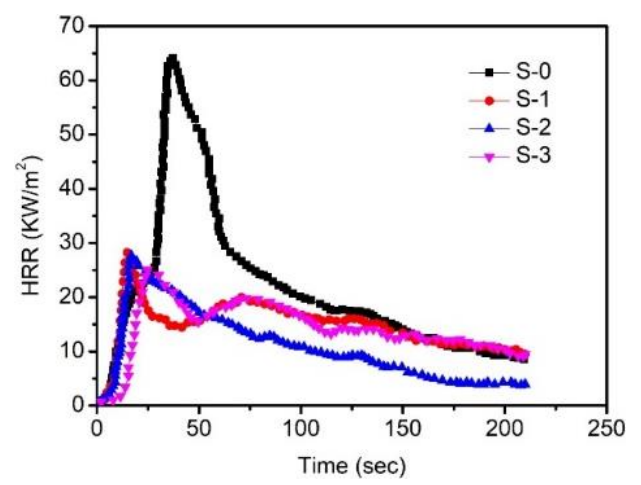

Figure 5. Heat release rate (HRR) curves of all four samples

The thermal conductivity coefficients of all samples were examined to reveal the impacts of $\mathrm{TiO}_{2}$ doping and modification on the flame retardancy of cellulose aerogel. The resulting thermal conductivity coefficient curves are displayed in Figure 4. According to national standards, the thermal conductivity of insulation materials should be fewer than $0.174 \mathrm{~W} /(\mathrm{m} \cdot \mathrm{k})$ [13]. Figure 4 shows that the thermal conductivity coefficients of all four samples fell in the range of $0.002 \sim 0.004 \mathrm{~W} /(\mathrm{m} \cdot \mathrm{k})$. Thus, all the samples satisfy the requirements of standard insulation materials. Furthermore, $\mathrm{S}$ 1, S-2 and S-3 had a lower thermal conductivity than S-0, and the thermal conductivity of cellulose aerogel gradually decreased with the increase of $\mathrm{TiO}_{2}$ doping amount. These indicate that $\mathrm{TiO}_{2}$ doping and modification can reduce the thermal conductivity and enhance thermal insulation of cellulose aerogel. The total thermal conductivity of a material consists of solid-phase heat conduction, vapor-phase heat 
conduction and radiant heat conduction. Specifically, radiant heat conduction transfers heat across separated places. The radiant thermal conductivity is negatively correlated with thermal insulation property [14]. Solid-phase heat conduction is an inherent property of all materials that changes with material density [15]. With a porous structure, $\mathrm{TiO}_{2} / \mathrm{CNC}$ aerogels have a low density. Thus, there are many channels for heat transfer in the skeleton of the samples. Hence, the thermal conductivity of $\mathrm{TiO}_{2} / \mathrm{CNC}$ aerogels is mainly affected by the thermal conductivity of the solid phase [16].

The HRRs of all samples were measured by the cone calorimeter to further disclose the effects of $\mathrm{TiO}_{2}$ doping and modification on the flame retardancy of cellulose aerogel. The time-varying HRR curves of all samples are shown in Figure 5. The peak HRR (PHRR) is the key indicator of material flammability. In general, the lower the PHRR of a material, the better its flame retardance [17-21]. Figure 5 shows that the HRRs of S-0, S-1, S-2 and S-3 were $64 \mathrm{KW} / \mathrm{m}^{2}, 28 \mathrm{KW} / \mathrm{m}^{2}$, $27 \mathrm{KW} / \mathrm{m}^{2}$ and $25 \mathrm{KW} / \mathrm{m}^{2}$, respectively. The PHRRs of S-1, S-2 and S-3 were respectively $56.25 \%, 57.81 \%$, and $60.93 \%$ lower than that of S-0. The test results demonstrate that $\mathrm{TiO}_{2}$ doping and modification can effectively reduce the HRR and enhance the flame retardance of cellulose aerogel.

\section{CONCLUSIONS}

This paper successfully prepares $\mathrm{TiO}_{2}$-modified $\mathrm{CNC}$ composite aerogel through in-situ synthesis of $\mathrm{TiO}_{2}$ in $\mathrm{CNC}$ solution and supercritical $\mathrm{CO}_{2}$ drying, and carries out various tests on the pure $\mathrm{CNC}$ aerogel and $\mathrm{CNC}$ aerogel modified by different amounts of $\mathrm{TiO}_{2}$. The test results show that the $\mathrm{TiO}_{2-}$ modified $\mathrm{CNC}$ aerogels exhibited a $3 \mathrm{D}$ network structure and underwent a decline in crystallinity through $\mathrm{TiO}_{2}$ doping and modification. The $\mathrm{TiO}_{2} / \mathrm{CNC}$ aerogels surpassed the $\mathrm{CNC}$ aerogel in both thermal decomposition temperature $\left(216^{\circ} \mathrm{C}\right.$, $223^{\circ} \mathrm{C}$ and $239^{\circ} \mathrm{C}$ vs. $\left.213^{\circ} \mathrm{C}\right)$ and MTDR $\left(264^{\circ} \mathrm{C}, 265^{\circ} \mathrm{C}\right.$ and $280^{\circ} \mathrm{C}$ vs. $255^{\circ} \mathrm{C}$ ). The thermal conductivity of all cellulose aerogels meets the requirements of the national standards for thermal insulation materials. Specifically, $\mathrm{TiO}_{2} / \mathrm{CNC}$ aerogels had a lower thermal conductivity than the CNC aerogel, and the thermal conductivity of cellulose aerogel gradually decreased with the increase of $\mathrm{TiO}_{2}$ doping amount. Moreover, $\mathrm{TiO}_{2} / \mathrm{CNC}$ aerogels lagged behind the $\mathrm{CNC}$ aerogel in the PHRR. To sum up, the test results demonstrate that $\mathrm{TiO}_{2}$ doping and modification is an effective way to enhance the flame retardant and thermal insulation properties of cellulose aerogel. The research findings shed new light on the development of thermal insulation and fire-retardant clothing materials.

\section{ACKNOWLEDGMENT}

This work was supported financially by the Yunnan Science and Technology Plan Surface Project of China (No. 2015FB151).

\section{REFERENCES}

[1] Yuan B, Zhang J, Yu J, Song R, Mi QY, He JS, Zhang J. (2016). Transparent and flame retardant cellulose/aluminum hydroxide nanocomposite aerogels
Science China Chemistry 59(10): 1-7. https://doi.org/10.1007/s11426-016-0188-0

[2] Kaya M. (2017). Super absorbent, light, and highly flame retardant cellulose-based aerogel cross linked with citric acid. Journal of Applied Polymer Science 134(38): 45315. https://doi.org/10.1002/app.45315

[3] Fan B, Chen S, Yao Q, Sun Q, Jin C. (2017). Fabrication of cellulose nanofiber/AlOOH aerogel for flame retardant and thermal insulation. Materials 10(3): 311 . https://doi.org/10.3390/ma10030311

[4] Shang K, Liao W, Wang YZ. (2017). Thermally stable and flame-retardant polyvinyl alcohol/montmorillonite aerogel via, a facile heat treatment. Chinese Chemical Letters 29(3): 433-436. https://doi.org/10.1016/j.cclet.2017.08.017

[5] Wu YQ, Tian CH, Qing Y, Yao CH, Li XG, Yang SL. (2014). Preparation and properties of APP-SiO2 aerogel/poplar wood composite with excellent flame retardant. Journal of Functional Materials 45(14): 1411314117.

[6] Hribernik S, Smole MS, Kleinschek KS. (2007). Flame retardant activity of $\mathrm{SiO} 2$-coated regenerated cellulose fibres. Polymer Degradation \& Stability 92(11): 19571965.

[7] Ravi M, Samuelson L, Smith K, Westmoreland P, Parmar V, Yan F, Kumar J, Watterson A. (2008). Nanocomposites of $\mathrm{TiO} 2$ and Siloxane Copolymers as Environmentally Safe Flame-Retardant Materialsâ. Journal of Macromolecular Science: Part A - Chemistry 45(11): 942-946. https://doi.org/10.1080/10601320802380208

[8] Moafi HF, Shojaie AF, Zanjanchi MA. (2011). Flameretardancy and photocatalytic properties of cellulosic fabric coated by nano-sized titanium dioxide. Journal of Thermal Analysis \& Calorimetry 104(2): 717-724. https://doi.org/10.1007/s10973-010-1133-x

[9] Xue CH, Zhang L, Wei P, Jia ST. (2016). Fabrication of super hydrophobic cotton textiles with flame retardancy. Cellulose 23(2): 1471-1480. https://doi.org/10.1007/s10570-016-0885-2

[10] Li J, Zheng H, Sun Q, Han S, Fan B, Yao Q, Yan C, Jin C. (2015). Fabrication of super hydrophobic bamboo timber based on an anatase $\mathrm{TiO}_{2}$ film for acid rain protection and flame retardancy. Rsc Advances 5(76): 62265-62272. https://doi.org/10.1039/C5RA09643J

[11] Vasiljević J, Tomšič B, Jerman I, Orel B, Jakša G, Simončič B. (2014). Novel multifunctional water- and oil-repellent, antibacterial, and flame-retardant cellulose fibres created by the sol-gel process. Cellulose 21(4): 2611-2623. https://doi.org/10.1007/s10570-014-0293-4

[12] Ning Y, Deng H, Ping YU. (2012). Study on nano- $\mathrm{TiO}_{2}$ for flame-retardant finishing of cotton fabric. Journal of Tianjin Polytechnic University.

[13] Dogan M. (2014). Thermal stability and flame retardancy of guanidinium and imidazolium borate finished cotton fabrics. Journal of Thermal Analysis \& Calorimetry 118(1): 93-98. https://doi.org/10.1007/s10973-0143950-9

[14] Zheng Z, Liu Y, Zhang L, Wang H. (2016). Synergistic effect of expandable graphite and intumescent flame retardants on the flame retardancy and thermal stability of polypropylene. Journal of Materials Science 51(12): 5857-5871. https://doi.org/10.1007/s10853-016-9887-6 
[15] Guo L, Chen Z, Lyu S, Fu F, Wang S. (2018). Highly flexible cross-linked cellulose nanofibril sponge-like aerogels with improved mechanical property and enhanced flame retardancy. Carbohydr Polym 179: 333340. https://doi.org/10.1016/j.carbpol.2017.09.084

[16] Han Y, Zhang X, Wu X, Lu C. (2015). Flame Retardant, Heat Insulating Cellulose Aerogels from Waste Cotton Fabrics by in Situ Formation of Magnesium Hydroxide Nanoparticles in Cellulose Gel Nanostructures. Acs Sustainable Chemistry \& Engineering 3(8): 1853-1859. https://doi.org/10.1021/acssuschemeng.5b00438

[17] Yuan B, Zhang JM, Mi Q, Yu J, Song R, Zhang J. (2017). Transparent Cellulose-silica composite aerogels with excellent flame retardancy via in situ sol-gel process. Acs Sustainable Chemistry \& Engineering 5(11): 1111711123. https://doi.org/10.1021/acssuschemeng.7b03211

[18] Mukherjee S, Mishra PC, Chaudhuri P, Banerjee G. (2018). Theoretical modeling and optimization of microchannel heat sink cooling with $\mathrm{TiO} 2-$ water and
$\mathrm{ZnO}$-water nanofluids. International Journal of Heat and Technology 36(1): 165-172. https://doi.org/10.18280/ijht.360122

[19] Sun QF, Lu Y, Xia YZ, Yang DJ, Li J, Liu YX. (2012). Flame retardancy of wood treated by $\mathrm{TiO} 2 / \mathrm{ZnO}$ coating. Surface Engineering 28(8): 555-559. https://doi.org/10.1179/1743294412Y.0000000027

[20] Yang YX, Zhang CY, Huang YW, Guo YS, Xu JY. (2016). The design and research of a creative automatic bouncing socket. Mathematical Modelling of Engineering Problems 3(2): 67-70. https://doi.org/10.18280/mmep.030204

[21] He C, Huang J, Li S, Meng K, Zhang L, Chen Z, Lai Y. (2018). Mechanical Resistant and Sustainable Cellulosebased Composite Aerogels with Excellent Flame Retardant, Sound-absorption and Super-anti-wetting Ability for Advanced Engineering Materials. Acs Sustainable Chemistry \& Engineering 6(1): 927-936. https://doi.org/10.1021/acssuschemeng.7b03281 